\title{
Kompleks İntihar Olgusunda Kan Lekesi Model Analizi ile Olay Yerinin Yeniden Yapılandırılması
}

\author{
Death Scene Reconstruction Through Bloodstain Pattern Analysis on a Complex \\ Suicide Case
}

\author{
Murat Nihat Arslan, Mehmet Özbay, Bülent Şam
}

Adli Tıp Kurumu Başkanlı̆̆l, İstanbul

\begin{abstract}
Özet
İki veya daha fazla yöntemin eş zamanlı ya da peşi sıra uygulanması kompleks intihar olarak adlandırılmaktadır. Tek başına kullanıldığında da sonuca ulaşılabilecek iki farklı yöntemin intihar amaçlı kullanılması ölme güdülenmesindeki kararlılığı göstermektedir.

40 yaşındaki erkek olgumuz kurusıkıdan dönüştürülmüş bir silah ile kalbine ateş etmiş ve bu sırada kendini asmıştır. Otopside elde edilen bulgular, olay yeri inceleme raporundan alınan bilgiler, vücuttaki ve olay yerindeki kan lekeleri olay orijininin intihar olduğunu düşündürmüştür.

Kompleks intihar olgularında olayın orijinini ortaya çıkarma çalışmaları otopsi masasına geldikten sonra değil, olay yeri incelemesinde, hatta ceset ilk görüldüğü andan itibaren başlamalıdır. Olay yerinin multidisipliner olarak ele alınması, ortamda bulunabilecek her nesnenin/ delilin olayın çözümünde yardımının olabileceğinin akılda tutulması orijin tayininin kolaylıkla yapılmasını sağlayacaktır. Benzer şekilde otopsi yapılacak olan bir cesedin, varsa elbiseleri üzerindeki, yoksa vücudu üzerindeki kan lekelerinin kan lekesi model analizi yöntemleri ile dikkatli bir şekilde incelenmesi ve belgelendirilmesi de orijin tayininde faydalı bilgiler verebilmektedir.
\end{abstract}

Anahtar kelimeler: Kompleks İntihar; Ası; Dönüştürülmüş Kurusıkı Tabanca Yaralanması; Kan Lekesi Model Analizi; Orijin.

\begin{abstract}
Using two different methods for suicide, which are usually dangerous-enough for death singly shows the consistency of the desire of death. A 40-year-old man hung himself by shooting through the heart with a converted blank-cartridge gun. Autopsy findings, crime scene investigation findings, bloodstains on the body and the scene made us think that the manner of the death was the suicide.

Determining the manner of the death on complex suicide cases should be done before the autopsy with the contribution of crime scene findings. Handling the crime scene findings with a multidisciplinary aspect, considering every object or evidence on the crime scene as a useful tool to solve the case, may facilitate to determine the manner of death. Similarly, when approaching to the deceased at the autopsy room, examination and documentation of bloodstains on the clothes or on the body may provide useful information on determining the manner of the death.
\end{abstract}

Keywords: Complex Suicide; Hanging; Converted Blank Cartridge Gun Wound; Bloodstain Pattern Analysis; Manner of the Death.

(1). Adli tıp literatüründe çeşitli yöntemlerin kullanıldığ planlı kompleks intihar olguları bulunmaktadır (2-9). Çok tercih edilen ve tek başına uygulandığında da ölüm oranı oldukça yüksek olan intihar metotları arasında ası, kesici delici alet, ateşli silah, elektrik devreleri kullanımı, zehirli maddenin vücuda alınması yer almaktadır (10). Literatürdeki kompleks intihar olguları da bu s1k tercih edilen yöntemlerin iki ya da daha fazlasının bir arada kullanıldığı olgulardır. Ası ve ateşli silah kullanımı; ası ve kesici delici alet kullanımı, madde alınması ile yüksekten atlama gibi yöntemlerin kullanıldığı kompleks intihar olgularına literatürde rastlanabilmektedir (2-9,11-14).

Kompleks intihar olguları, intiharın sosyal tıbbi yönünün yanı sıra adli açıdan da önem taşımaktadır. İntihar olgularında ölümü açıklayabilecek birden fazla bulgu varlığı, soruşturmacıda olayın orijini konusunda şüphe doğmasına neden olabilecektir. Soruşturmanın derinleş-
Sorumlu Yazar: Uzm. Dr. Murat Nihat Arslan

Adli Tip Kurumu Başkanliğı, İstanbul

E-mail:mnarslan@yahoo.com

Geliş:24.11.2015 Düzeltme:11.02.2016 Kabul:19.04.2016 
tirilmesi ve faydalı olabilecek tüm adli bilimler disiplinlerinden yararlanılması, oluşacak bu şüpheleri en aza indirgeyebilecek ya da ortadan kaldırabilecektir. Buradan yola çıkarak, kan lekesi model analizi ile olayın oluş anına ilişkin ipuçları elde edilebilmiş bu kompleks intihar olgusunun adli bilimler profesyonelleri ile paylaşılması ile konuya dikkat çekilmesi hedeflenmiştir.

\section{Olgu}

Ası ve ateşli silah yaralanması sonucu intihar ettiği hikâyesi ile otopsi yapılmak üzere Adli Tıp Kurumu Morg İhtisas Dairesine gönderilmiş olan kırk yaşında erkek olgunun soruşturma dosyası, olay yeri inceleme raporu ve olay yerinde çekilmiş olan fotoğrafları; otopsi bulguları, otopsi sırasında çekilmiş olan fotoğraflar bir arada irdelenmiştir.

\subsection{Olay Yeri İnceleme Raporu}

Olay Yeri İnceleme Büro Amirliğinin raporunda; olay yerine girildiğinde olay yerinde intihar notu bulunduğu, .... şahsın doğalgaz borusuna $1 \mathrm{~cm}$ çapında 3 metrelik ip ile asılı vaziyette, yüzü duvara dönük, ayakları yere basar ve dizleri hafif şekilde bükük, vücudu duvara yapışık, ayakları arasında kurumuş kan birikintisi görüldüğü, kan birikintisi içinde bir adet siyah renkli, siyah plastik kabzalı bilye atar olarak tabir edilen tabanca olduğu, ... ası ipinin bağlandığı doğalgaz borusu ile zemin arasının $264 \mathrm{~cm}$, boru ile şahsın boynu arası $83 \mathrm{~cm}$, şahsın boyunun $177 \mathrm{~cm}$ olarak ölçüldüğü, ... şahsın göğsünden akan kan ile üzerinde bulunan giysilerin ön kısmının tamamen kana bulanmış, şahsın yüzüne bakan duvarda yoğun şekilde kan olduğu bildirilmiştir (Resim 1).
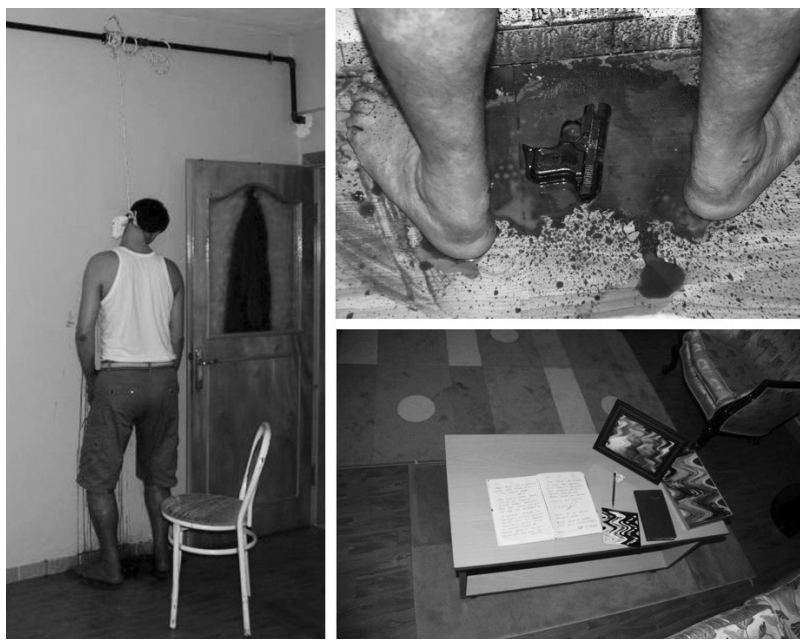

Resim 1. Sol: Cesedin olay yerinde bulunuş pozisyonu (duvardaki ve yerdeki kan lekesi modeli); Sağ üst: Ceset bulunduğunda tabancanın ve kan lekelerinin pozisyonu; Sağ alt: İntihar notu.

\section{2. Ölü muayenesi ve otopsi}

Otopsi öncesi yapılan radyolojik incelemesinde gögüs sol yarısında dairesel görünümlü metalik cisim imajı tespit edildi. Olgunun dış muayenesinde boyunda tiroid kıkırdak üst seviyesinde, en geniş yeri boyun sol yarısında bulunan, boynun her iki yanından arkaya ve hafif yukarı doğru uzanan ve oksipital solda yükselip yüzeyselleşerek, birleşerek sonlanan, boyun sol yarısında kısmen kesintiye uğrayan telem görüldü. Teleme ek olarak sol meme başının $4,8 \mathrm{~cm}$ iç yanında, etrafında vurma halkası ve stampa izi bulunan ateşli silah giriş yarası izlendi. Dış muayenede dikkati çeken bulgulardan birisi de vücuttaki kan lekeleriydi. Her iki ayak sırtında yaygın ikincil kan lekeleri ve ayak tabanlarında kılcal etki (kapiller aktivite) göstermiş kan lekesi modeli izlendi.

Olgunun iç muayenesinde göğüs cildi altında solda dış muayenede tespit edilen ateşli silah giriş yarasının altına uyan bölgede Hoffmann maden boşluğu görüldü. Solda 4. interkostal aralık ile midklaviküler hat kesişim yerinde $1 \mathrm{~cm}$ çapında göğüs boşluğu ile iştirakli defekt olduğu görüldü. Sol plevral boşluktan $1000 \mathrm{~mL}$, perikard boşluğundan ise $300 \mathrm{~mL}$ kan boşaltıldı. 8. gögüs omuru içerisinde makroskopik görünümüne göre $4 \mathrm{~mm}$ çapında ölçülen küresel metalik bilye olduğu görüldü. Metalik bilyenin gögüs içerisinde kalbin sol ventrikül ön duvarını ve torakal aortu delerek ilerlediği tespit edildi.

Boyun bölgesinin incelenmesinde hyoid kemik sol boynuzunda ekimozlu kırık ile çevre yumuşak dokularda kanama olduğu görüldü. Tiroid kıkırdak ve boyun omurları sağlam bulundu.

\subsection{Laboratuvar İncelemeleri}

Yapılan toksikolojik analizde kanda alkol (Etanol, Metanol) ya da herhangi bir uyutucu-uyuşturucu madde saptanmadığ 1 bildirildi. Her iki elden alınan svap örneklerinin atış artıkları yönünden incelenmesine dair sonuçlar Tablo 1'de gösterilmiştir.

Tablo 1. Cesetten alınan svap örneklerinde saptanan Kurşun ve Antimon değerleri

\begin{tabular}{|l|l|l|}
\hline Örnek & Toplam Kurşun & Toplam Antimon \\
\hline Sol el sırtı & $234,12 \mathrm{ng}$ & $35,72 \mathrm{ng}$ \\
\hline Sol el avuç içi & $212,47 \mathrm{ng}$ & $16,53 \mathrm{ng}$ \\
\hline Sağ el sırtı & $128,96 \mathrm{ng}$ & - \\
\hline Sağ el avuç içi & $100,19 \mathrm{ng}$ & $17,37 \mathrm{ng}$ \\
\hline
\end{tabular}




\subsection{Olay Yerindeki ve Cesedin Vücudundaki Kan Lekelerinin Yorumlanması}

Cesedin ayak sırtlarında ve ayak bileklerinde çok sayıda kan lekesi görülmüş olup olay yeri incelemesi raporunda da belirtilen bulgular ile birlikte düşünüldüğg̈nde bu leke modelinin ikincil kan damlaları ile oluşan lekeler olduğu kanısına varılmıştır. Ateşli silah giriş yarasından açığa çıkan kanın yerçekimi etkisiyle yere akarak kan gölü oluşturduğu ve bu kan gölü içerisine doğru kan akmaya devam ettikçe bu kan gölünden sıçrayarak ikincil kan damlaları doğmasına neden olduğu düşülmüş̧ür (15). Sıçrayan ikincil kan damlaları da kan gölü içerisinde/çevresinde bulunan her iki ayağın sırtında ikincil lekeler oluşumuna neden olmuştur (Resim 2 sağ). Bununla birlikte olay yeri incelemesi raporunda tarif edilenleri destekler şekilde her iki ayak tabanında görülen ve kılcal etki (kapiller aktivite) nedeniyle oluşmuş kan lekesi modeli cesedin her iki ayağının da en azından bir kısmının yer ile temas halinde olduğunu göstermektedir (Resim 2 sol).

Birbirine temas halinde bulunan iki yüzey arasında kalan kan, bu iki yüzey birbirinden ayrılmaktayken yüzey gerilimi kuvveti yenilene kadar birbirinden ayrılmaz ve iki yüzey arasında bir köprü oluşturur. Bu etki kılcal etki olarak adlandırılmakta olup (15) yüzeyler birbirinden bütünü ile ayrıldığında olgumuzun ayak tabanlarında görüldüğü şekilde tipik bir leke modeli oluşturur. Ayrıca her iki ayak tabanında bulunan kan lekesiz alanlar da bu bölgelerin kan dökülmeye başlamadan önce yer ile bütünü ile temas eden bölgeler olduğunu, ardından ayakların altında kan biriktikçe zemin ile sıkıca temas halinde olmayan bölgelere kan dolduğunu göstermektedir.

Olay yeri fotoğraflarının incelenmesinde de cesedin ipte asılı vaziyetteyken ayaklarının yere temas ettiği ve kişinin çıplak ayaklı olduğu, yüzünün duvara dönük ve vücudunun bir kısmının duvar ile temas halinde olduğu, ateşli silah giriş yarasından çıkan kanın duvarda bir akma modeli oluşturarak yere ulaştığı ve yere damlama neticesinde oluşan kan gölünden etrafa doğru bir damlama modeli oluştuğu görüldü. Cesedin ayaklarında saptanan ikincil leke modelinin bir benzeri ayakların hemen önünde bulunan duvarda da oluşmuş olduğu görüldü.

Vücuttaki ve olay yerindeki kan lekeleri sonuç olarak kişinin yaralanması meydana geldiği anda ayakta durduğunu, yüzünün duvara dönük olduğunu göstermiştir.

Olgumuzun ölümünün ası ve ateşli silah yaralanmas1na bağlı, omur kırığıyla birlikte iç organ ve büyük damar delinmesinden gelişen iç kanamanın ortak etkisi sonucu meydana gelmiş olduğu kanaatine varıldı. Soruşturmacı tarafindan yapılan geri bildirimle de olayın intihar olarak değerlendirildiği ve dosyanın bu şekilde kapanmış olduğu öğrenildi.

\section{Tartışma}

İntihar vakalarında birden fazla yöntem kullanımı çok sık karşıllaşılmamakla birlikte derinlemesine inceleme gerektiren adli olgulardandır. Her ne kadar olgumuzun psikiyatrik antesedanı ile ilgili bilgi bulunmamakta ise de bu tarz çoklu yöntemin kullanıldığı intihar olgularında, önceden var olan kişilik bozukluğu, depresyon, madde kullanımı veya şizofreni gibi psikiyatrik hastalıklara siklıkla rastlanmaktadır $(3,5,16)$. Bu nedenle de olayın orijini aydınlatılmaya çalışılırken psikiyatrik özgeçmişin sorgulanması; olgunun bu tarz bir ölüm yolunu seçme konusunda risk grubunda olup olmadığını açığa çıkarabilecektir.

Türkiye İstatistik Kurumunun 2011 yılı verilerine göre ülkemizde intihar için en çok tercih edilen yöntem \%51,9 oranı ile asıdır (2011 yılında kayıtlara geçmiş 2677 olgunun 1391 'i). İkinci sırada ise \%26,1 oranı ile ateşli silah kullanımı gelmektedir (2677 olgunun 698'i) (17).

Olgumuzca tercih edilmiş olan intihar yöntemlerinden birisi olan kurusıkı silah kullanımı ayrıca tartışılmalıdır. Kurusıkı silahlar basit birkaç modifikasyonun ardından
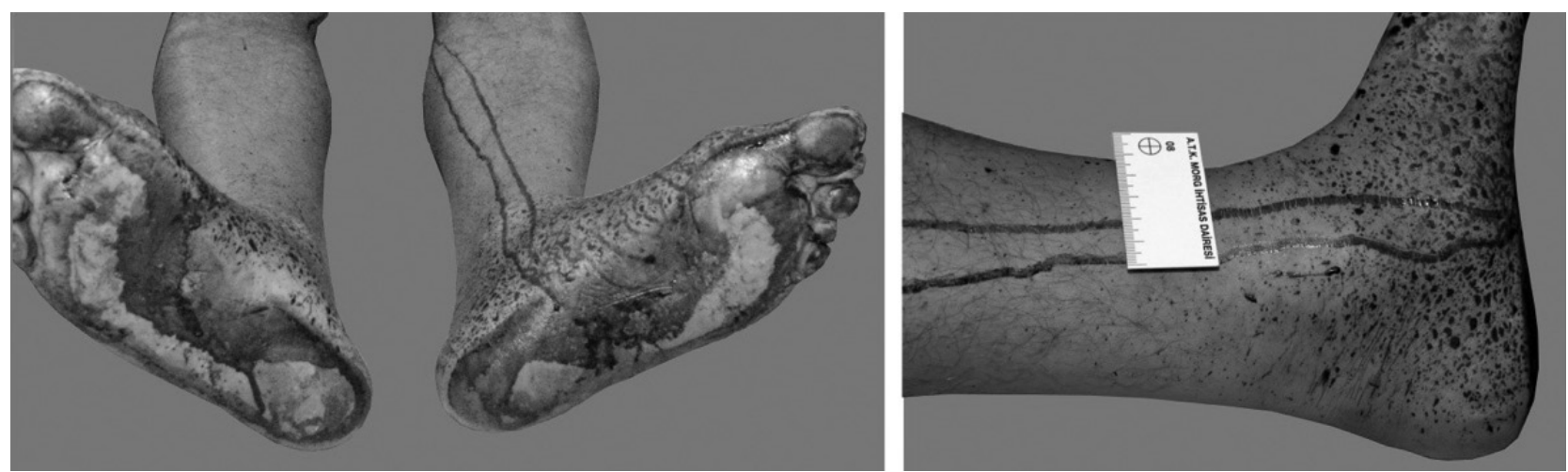

Resim 2. Sol: Ayak tabalarındaki kapiller aktivite modeli; Sağ: Ayak sırtındaki ikincil kan lekelerinin oluşturduğu model. 
kolay elde edilebilir ve ölümcül silahlar haline gelebilmektedir. Literatürde modifiye edilmiş kurusıkı silahlar ile meydana gelen ölümler bildirilmiştir $(18,19)$.

Temel olarak intihar amaciyla birden fazla yöntem kullanımı ölme niyetindeki kararlılığı göstermekte ise de bu tür olgular ile karşılaşıldığında soruşturmada intiharın yanında cinayet olasılığının da akıldan çıkarılmaması gerekmektedir.

Her ne kadar literatürde benzer olgular ile karşıllaş1labiliyor olsa da ölümü açıklayabilecek birden fazla yöntem var ise olayın cinayet olabileceği akıldan çıkarılmamalıdır $(4,10,11)$. Tek yöntemin kullanıldığı basit intihar olgularında olduğu gibi kompleks intihar olgularında da tüm ayırıcı bulgular dışlandıktan sonra soruşturma intihar yönüne çevrilmelidir. Otopside elde edilen bulgular olayın kesin orijini hakkında her zaman tam olarak bilgi sağlayamamaktadır. Bu yüzden olgunun orijin tayini için yapılacak incelemeler ceset otopsi masasına alındıktan sonra değil, bulunduğu andan itibaren yapılmaya başlanmalıdır.

Eksiksiz ve multidisipliner yaklaşımla yapılacak olay yeri incelemesi, henüz otopsiye gönderilmeden otopsi sırasında cesede nasıl yaklaşılması gerektiğini belirleyecektir. Bu noktada ülkemizde karşılaşılan en büyük engel olay yeri incelemesinin ve delil toplama sürecinin otopsiyi yapacak hekimlerin kontrolü ve bilgisi dışında yapılmasıdır. Bu tarz olguların çözümünde en önemli noktalardan birisi olay yerine hekimlerin de davet edilmesi, soruşturmanın takibinin ve yönetiminin hekimin direktiflerine göre yürütülmesidir.

Olgumuzda olduğu gibi cesedin olay yerindeki konumu ve pozisyonu ölümün sebebi ve orijini ile ilgili çok önemli ipuçları verebilmektedir. Otopsi sırasında cesedin ayaklarında saptanan kan lekesi modelleri; olay yeri incelemesi sırasında çekilmiş fotoğrafların incelenmesi sonucu tespit edilmiş kan lekesi modelleri kişinin olay anındaki pozisyonunu ortaya çıkarmıştır. Benzer pek çok olguda olay yerindeki kan lekeleri hak ettiği değeri görememekte ve soruşturmaya yapabileceği katkılardan habersiz incelemeciler tarafindan atlanmaktadır.

Olay yerinin/anının yeniden yapılandırılması adı verilen ve olay anında mağdurun, ölenin, failin ve olay yerindeki diğer tüm nesnelerin pozisyonlarının belirlenmesi ve birbirine göre konumlandırılması sürecinin beslendiği disiplinlerden birisi de kan lekesi model analizidir $(15,16,20)$. Sunulan bu olguda da dönüştürülmüş kurusık1 tabanca ateşlendiği anda kişinin pozisyonu hakkında olay orijininin intihar olarak değerlendirilebilmesini sağlayan bilgiler vermiştir.

Olay yeri belgelendirilmesinin (kroki, fotoğraflama ve kamera kaydı gibi) eksiksiz ve doğru yapılması; fiziki ve biyolojik delillerin özenle toplanması ve birçok farklı olay yeri inceleme disiplininden faydalanılarak olay yerinin/anının yeniden yapılandırılması otopsiyi yapacak ve olay yerini görme şansı bulunmayan hekimin işini oldukça kolaylaştıracaktır.

\section{Kaynaklar}

1. Racette S, Sauvageau A. Planned and unplanned complex suicides: A 5-year retrospective study, Journal of Forensic Sciences 2007; 52(2):449-52. DOI: 10.1111/j.15564029.2007.00387.x

2. Slobodan N, Vladimir Ž, Fehim J. Unplanned complex suicide--two case reports, Srp Arh Celok Lek 2010;138(56):371-5. DOI: 10.2298/SARH1006371N

3. Germerott T, Jaenisch S, Hatch G, Albrecht UV, Guenther D. Planned complex suicide: Self-strangulation and plaster ingestion. Forensic Sci Int 2010; 202(1-3):35-7. doi: 10.1016/j.forsciint.2010.04.053

4. Altun G. Planned complex suicide: Report of three cases. Forensic Sci Int 2006;157(2):83-6. doi: 10.1016/j.forsciint.2005.04.039

5. Nadjem H, Weinmann W, Pollak S. Ingestion of pointed objects in a complex suicide. Forensic Sci Int 2007;171(1):114. doi: 10.1016/j.forsciint.2007.05.002

6. Ruwanpura R. A complex suicide. Ceylon Med J 2009; 54(4):132-4. DOI: 10.4038/cmj.v54i4.1457

7. Pélissier-Alicot AL, Gavaudan G, Bartoli C, Kintz P, Piercecchi-Marti MD, Desfeux L, Leonetti G. Planned complex suicide: an unusual case. J Forensic Sci 2008; 53(4):968970 DOI: $10.1111 /$ j.1556-4029.2008.00754.x

8. Türk EE, Anders S, Tsokos M. Planned complex suicide: Report of two autopsy cases of suicidal shot injury and subsequent self-immolation. Forensic Sci Int 2004; 139(1):33538 doi: 10.1016/j.forsciint.2003.09.013

9. Viela G, Schröder AS, Püschel K, Braun C. Planned complex suicide by penetrating captive-bolt gunshot and hanging: Case study and review of the literature, Forensic Sci Int 2009;187(1):7-11. doi: 10.1016/j.forsciint.2009.01.022

10. Kanchan T, Menon A, Menezes RG. Methods of choice in completed suicides: Gender differences and review of literature. J Forensic Sci 2009; 54(4):938-942 DOI: 10.1111/j.1556-4029.2009.01054.x

11. Demirci S, Doğan KH, Erkol Z, Deniz I. A series of complex suicide. Am J Forensic Med Pathol 2009; 30(2):152154. doi: 10.1097/PAF.0b013e318187deb7

12. Blanco-Pampin J, Suárez-Peñaranda JM, Rico-Boquete R, Concheiro-Carro L. Planned complex suicide: An unusual suicide by hanging and gunshot. Am J Forensic Med Pathol 1997; 18(1):104-106.

13. James SH, Kish PE, Sutton TP. Principles of Bloodstain Pattern Analysis. Theory and Practice. 1st ed. Boca Raton: CRC Press Inc.; 2005. p.71-87.

14. Özdemir Ç, Tuğcu H, Asil H, Din H. As1 ve yanık kombinasyonlu primer kompleks intihar: olgu sunumu. Adli Tip Bülteni 2006;11(2):75-9. doi: 10.17986/blm.2006112611

15. Bevel T, Gardner RM. Bloodstain Pattern Analysis: With an Introduction to Crime Scene Reconstruction. 2nd ed. Boca Raton: CRC Press Inc.; 2002: 78-80. 
16. M. Perdekamp MG, Pollak S, Thierauf A. Medicolegal evaluation of suicidal deaths exemplified by the situation in Germany. Forensic Sci Med Pathol 2010; 6:58-70. doi: 10.1007/s12024-009-9120-x

17. İntihar İstatistikleri 2011. Yayın No: 3695. Türkiye İstatistik Kurumu Matbaas1, Ankara, 2012.

18. Üzün İ, Büyük Y, Erkol Z, Ağrıtmış H, Kır Z. Fatalities caused by spherical bullets fired from blank cartridge guns in Istanbul, Turkey. J Forensic Sci 2009;54(5):1127-30 DOI: 10.1111/j.1556-4029.2009.01097.x

19. Özdeş T, Erkol Z, Cantürk N, Koçak U, Tekelioğlu Y. A case of accidental child death which occured with blank cartridge gun. Medicine Science 2014;3(2):1289-98. doi: 10.5455/ medscience.2013.02.8116

20. Aşıcıoğlu F, Arslan MN. Kan Lekesi Model Analizi: Olay Yerinin Yeniden Yapılandırılmasında Kan Lekesi Delili. İstanbul, Beta Kitap; 2009. 